Vol.45, Special n. : pp. 61-67, September 2002

ISSN 1516-8913 Printed in Brazil

\title{
The Clinical Impact of [18F]-FDG Pet During the Opening Year of a Pet Centre
}

\author{
Jean-Noël Talbot ${ }^{*}$ \\ Hôpital Tenon; 4 rue de Chine; F75970 Paris cédex 20; Paris-France; jean-noel.talbot@tnn.ap-hop-paris.fr
}

\begin{abstract}
We have evaluated the clinical impact of FDG-PET on patient staging and management during the opening year of our PET centre in France. A questionnaire, translation in French of the questionnaire used recently in California, was sent to the referring physician of each of the 476 patients who had at least one routine FDG-PET examination during the year 2000. Of 348 responses (response rate $=73 \%$ ), the disease was upstaged in 26\% of the cases and downstaged in 9\%. Inter-modality management changes (change from a scheduled therapeutic modality for a different one) were reported in $37 \%$ of the cases and intra-modality changes in $9 \%$. Those modification rates were respectively $38 \%$ and $7 \%$ in recurrence of colorectal cancer (153 patients), $47 \%$ and $7 \%$ in lung cancer (118 patients), $16 \%$ and 23\% in lymphoma (43 patients), 25\% and 6\% in the staging of head and neck cancers (32 patients). When comparing with the similar studies performed in California, there were no significant differences between the rates of inter-modality management changes. In contrast, intra-modality management changes were less frequent in our survey, except for lymphoma. Globally, the clinical impact of FDG PET was similar, with a higher response rate to our survey (73\% versus 35\%); it was above the mean $31 \%$ rate of therapeutic modification derived from a recent tabulated summary in over 3400 patients.
\end{abstract}

Key words: PET, [18F]-FDG, clinical impact, cancer

\section{INTRODUCTION}

The diagnostic performances of $[18 \mathrm{~F}]-\mathrm{FDG}$ derived from international literature lead in France at the end of 1998 to a marketing authorisation in precise clinical indications of five cancers: lung cancers and lymphomas at various moments of their evolution, melanoma and head and neck cancers at staging, colorectal cancer at recurrence. This marked one important success for pioneer teams like ours who had performed routine PET examinations for several years using a CDET gamma-camera and also marked the starting point for the development of clinical PET in France using dedicated machines. One year later, we were granted a dedicated PET machine in conjunction with 4 other nuclear medicine departments of Paris and suburbs. We decided to ask the referring physicians to precise the clinical impact of FDG PET for the staging and the management of their patients by means of a questionnaire survey covering the year 2000, opening year of the "centre TEP AP-HP" (Paris hospitals PET c entre).

\footnotetext{
${ }^{*}$ Author for correspondence
} 


\section{MATERIALS AND METHODS}

\section{Patients}

Since the opening of Centre TEP AP-HP, on the $11 / 01 / 2000$, until the $31 / 12 / 2000$, 605 patients have benefited from $656[18 \mathrm{~F}]-\mathrm{FDG}$ PET examinations. After excluding those examinations performed as part of clinical assays for which a "spontaneous" modification was ruled out by the protocol, the target population consisted of 476 patients (Table 1). One single questionnaire per patient was sent to the referring clinician, to avoid "re-sampling" and to adjust the study at the "patient" level.

\section{[18F]-FDG PET examination}

The patient was instructed to fast for $6 \mathrm{~h}$ at least with a normal fluid, intake. He/she was installed in a comfortable supine position, to favour muscular rest and a saline infusion was installed. Approximately $20 \mathrm{~min}$ later, $2 \mathrm{MBq} / \mathrm{kg}$ body mass of [18F]-FDG was injected via the infusion, that was maintained for one hour to obtain a good hydratation of the patient. The infusion was then removed and the patient voided. The examination was subsequently started, beginning over the pelvis and scanning backwards for 7 to 9 bed positions. For each bed position, the emission acquisition lasted $6 \mathrm{~min}$ and the transmission acquisition, obtained by means of a cesium -137 source, lasted $2 \mathrm{~min}$. Acquisition was performed in 3D mode, without the use of septa. The typical duration of the examination was one hour. Images processing and reconstruction were then performed, using an OSEM algorithm, with 4 iterations and 8 subsets.

Table 1 - Repartition of the patients and response rate to the questionnaire survey, according to main clinical indication.

\begin{tabular}{lccc}
\hline Indications & $\begin{array}{c}\text { Patients } \\
\text { included }\end{array}$ & $\begin{array}{c}\text { Exploitable } \\
\text { questionnaires }\end{array}$ & $\begin{array}{c}\text { Response } \\
\text { rate to the } \\
\text { survey }\end{array}$ \\
\hline Colorectal & 220 & 153 & $70 \%$ \\
Lung & 153 & 118 & $77 \%$ \\
Lymphoma & 63 & 43 & $68 \%$ \\
Head and & 38 & 32 & $84 \%$ \\
neck & & & $(100 \%)$ \\
Melanoma & 2 & 2 & $77 \%$ \\
Global & 476 & 348 & \\
\hline
\end{tabular}

\section{Interpretation}

These routine examinations were interpreted by a nuclear medicine specialist, knowing the clinical context and the results of the other imaging examinations. No examination was re-read when subsequent examinations became available or when the therapeutic decision had been taken. The interpretation was purely visual, from both attenuation corrected and uncorrected slices and tridimensional rotating display. No semiquantitation by calculation of SUV was attempted.

\section{Questionnaire}

The questionnaire sent to the referring clinician is very simple. It consists of the French translation of the questionnaire used by two Californian teams to evaluate the clinical impact of PET, allowing a direct comparison of the results. One question addresses the impact of FDG PET on staging the patient and another on therapeutic decision making. For this last item, 4 therapeutic modalities are considered: surgery, radiation therapy, medical treatment and abstention. A ch ange reported by the referring clinician from one modality scheduled before PET examination to another is referred as an "inter-modality" or major change. A modification within the same modality, such as change of chemotherapeutic agent or regimen, surgical or radiotherapeutic protocol, will be referred as an "intra-modality" change. "No impact" was reported if the treatment scheduled prior to PET was maintained, irrespectively of the discovery of new lesions or of a better confidence of the clinician in his decision thanks to PET.

One questionnaire per patient and one reminder in case of no response were sent to every referring physician.

\section{RESULTS}

\section{Response rate to the survey}

When we closed the survey, at the end of June 2001, 348 exploitable questionnaires have been received, the effective response rate being $348 / 476=73 \%$. According to the primary tumour, this rate was $70 \%$ in colorectal cancer, $77 \%$ in lung cancer, $68 \%$ in lymphoma, $84 \%$ in head and neck cancers and $100 \%(2 / 2)$ in melanoma, an indication in whom patients were very 
infrequently referred for PET at that time in France (Table 1).

\section{Impact on staging}

A modification of the stage due to FDG-PET was reported in 123 of 348 cases, 35\%, consisting in an upstaging in $26 \%$ of the cases or a downstaging in $9 \%$ which was thus less frequent. Table 2 illustrates the distribution of this impact on staging according to the clinical indication. There was a trend to a more frequent downstaging in lung cancer.

\section{Impact on patient management}

Globally, such an impact was reported by the referring physician in 159 patients corresponding to $46 \%$. Inter-modality (major) changes in patient management were reported in 129 patients corresponding to $37 \%$ of the cases and intra- modality (minor) changes were reported less frequently, in 30 patients, $9 \%$ of the cases.

Table 3 illustrates the distribution of this impact on management according to the clinical indication. The most frequent impact was observed in lung cancer. Apart from lymphoma, intermodality changes most frequently involved surgery, consisting, as expected from literature, in cancellation mostly in relation with a more widespread disease than known before PET, but also in indication of surgery. Frequent examples of this "positive" impact of PET on surgical indications were the following: when a single focus was discovered in an occult recurrence of colorectal cancer leading to its resection or when an adrenal mass did not take-up FDG in a lung cancer patient, allowing the resection of the primary tumour.

Table 2 - Impact of [18F]-FDG PET on patient staging, according to main clinical indication (number of patients)

\begin{tabular}{lcccccc} 
& Colorectal & Lung & Lymphoma & $\begin{array}{c}\text { Head and } \\
\text { neck }\end{array}$ & Melanoma & Global \\
\hline No change & 100 & 71 & 30 & 22 & 2 & $\mathbf{2 2 5}$ \\
Upstaging & 45 & 28 & 10 & 7 & & $\mathbf{9 0}$ \\
Downstaging & 8 & 19 & 3 & 3 & & $\mathbf{3 3}$ \\
TOTAL & $\mathbf{1 5 3}$ & $\mathbf{1 1 8}$ & $\mathbf{4 3}$ & $\mathbf{3 2}$ & $\mathbf{2}$ & $\mathbf{3 4 8}$ \\
Impact rate & $\mathbf{3 5} \%$ & $\mathbf{4 0 \%}$ & $\mathbf{3 0} \%$ & $\mathbf{3 1} \%$ & $\mathbf{0} \%$ & $\mathbf{3 5} \%$ \\
\hline
\end{tabular}

Table 3 - Impact of [18F]-FDG PET on patient management, according to main clinical indication (number of patients)

Colorectal Lung Lymphoma Head and neck Melanoma Global

\begin{tabular}{|c|c|c|c|c|c|c|}
\hline No change & 85 & 55 & 26 & 22 & 1 & 189 \\
\hline Surgery remplaced & 20 & 33 & 1 & 3 & & 57 \\
\hline Surgery indicated & 20 & 10 & & 2 & & 32 \\
\hline $\begin{array}{l}\text { Other inter-modality } \\
\text { modification }\end{array}$ & 18 & 12 & 6 & 3 & 1 & 40 \\
\hline Intra-modality modification & 10 & 8 & 10 & 2 & & 30 \\
\hline TOTAL & 153 & 118 & 43 & 32 & 2 & 348 \\
\hline Impact rate & $44 \%$ & $53 \%$ & $40 \%$ & $31 \%$ & $50 \%$ & $46 \%$ \\
\hline
\end{tabular}

\section{DISCUSSION}

Our results (Table 4 and 5) have to be compared to those of studies including evaluation of the clinical impact published until year 2000 that have been summarised in a "tabulated" form by Gambhir et al. in 2001, which only refers to changes in patien $t$ management. They must also be compared to more recent impact studies that have been published since then. Among them, the most valuable comparison will be made with the data of the two Californian teams, since we used exactly the same approach of evaluation by the referring physician and the same questionnaire. The first abstract reporting the global results obtained by these Californian teams between November 1998 and December 1999 appeared at the SNM meeting of year 2000 (Seltzer et al., 2000). Their results in 
recurrent colorectal cancer (Meta et al., 2001) and lymphoma (Meta et al., 2001) were published later as full papers. But, to the best of our knowledge, their results in lung cancer have only been published in an abstract form at the SNM meeting of year 2001 (Schöder et al., 2001), their results in melanoma are still only available in an abstract form (Wong et al., 2001) and no specific data in head and neck cancers have been published. There are some similarities and some differences between their study and ours that has been performed one year later. Major indications are the same but lung cancer was more frequent in the
Californian study. The total number of patients was 476 in our study versus 1532 in the Californian bicentric study, but the re sponse rate was $73 \%$ in our study versus $35 \%$ only in the Californian study, leading to a more similar number of exploitable questionnaires (348 versus 536), with less risk in our study of the classical bias of questionnaire surveys: clinicians who are not satisfied by the examination do not respond. Finally, our study took place during the opening year of our PET centre using a dedicated camera while the Californian referring physicians had a longer opportunity to become familiar with PET.

Table 4 - Modification of patient staging. Comparison of the present study with the Californian studies using the same questionnaire.

\begin{tabular}{lcccc}
\hline & $\begin{array}{c}\text { AP-HP } \\
\text { upstaging }\end{array}$ & $\begin{array}{c}\text { AP-HP } \\
\text { downstaging }\end{array}$ & $\begin{array}{c}\text { California } \\
\text { upstaging }\end{array}$ & California downstaging \\
\hline GLOBAL & $26 \%$ & $9 \%$ & $28 \%$ & $14 \%$ \\
Colorectal & $90 / 348$ & $33 / 348$ & $150 / 536[2]$ & $75 / 536[2]$ \\
& $29 \%$ & $5 \%$ & $33 \%$ & $8 \%$ \\
Lung & $45 / 153$ & $8 / 153$ & $20 / 60[3]$ & $5 / 60[3]$ \\
& $24 \%$ & $16 \%$ & $24 \% *$ & $17 \% *$ \\
Lymphoma & $28 / 118$ & $19 / 118$ & $21 \%$ & $7 / 41[4]$ \\
& $23 \%$ & $7 \%$ & $11 / 52[5]$ & $23 \%$ \\
Head and neck & $10 / 43$ & $3 / 43$ & - & - \\
& $22 \%$ & $3 / 32$ & $17 \%[5]$ \\
Melanoma & $7 / 32$ & $(0 / 2)$ & $8 / 47[6]$ & $15 \%$ \\
& $(0 / 2)$ & & & $7 / 47[6]$ \\
\hline
\end{tabular}

* refers only to recurrent lung cancer

Table 5 - Modification of patient management. Comparison of the present study with literature.

\begin{tabular}{|c|c|c|c|c|c|}
\hline & $\begin{array}{c}\text { AP-HP } \\
\text { Inter-modality }\end{array}$ & $\begin{array}{c}\text { AP-HP } \\
\text { Intra-modality }\end{array}$ & $\begin{array}{c}\text { California } \\
\text { Inter-modality }\end{array}$ & $\begin{array}{c}\text { California } \\
\text { Intra-modality }\end{array}$ & $\begin{array}{l}\text { Tabulated summary } \\
\text { Gambhir et col [1] }\end{array}$ \\
\hline GLOBAL & $\begin{array}{c}37 \% \\
129 / 348\end{array}$ & $\begin{array}{c}9 \% \\
30 / 348\end{array}$ & $\begin{array}{c}43 \% \\
230 / 536[2]\end{array}$ & $\begin{array}{c}17 \% \\
91 / 536[2]\end{array}$ & $\begin{array}{c}31 \% * \\
1055 / 3405\end{array}$ \\
\hline Colorectal & $\begin{array}{c}38 \% \\
58 / 153\end{array}$ & $\begin{array}{c}7 \% \\
10 / 153\end{array}$ & $\begin{array}{c}37 \% \\
22 / 60[3]\end{array}$ & $\begin{array}{c}25 \% * * \\
15 / 60[3]\end{array}$ & $\begin{array}{c}32 \% \\
293 / 915\end{array}$ \\
\hline Lung & $\begin{array}{c}47 \% \\
55 / 118\end{array}$ & $\begin{array}{c}7 \% \\
8 / 118\end{array}$ & $\begin{array}{c}44 \% \\
120 / 273[2]\end{array}$ & $\begin{array}{c}14 \% \\
11 / 76[4]\end{array}$ & $\begin{array}{c}37 \% \\
579 / 1565\end{array}$ \\
\hline Lymphoma & $\begin{array}{l}16 \% \\
7 / 43\end{array}$ & $\begin{array}{c}23 \% \\
10 / 43\end{array}$ & $\begin{array}{c}42 \% \\
22 / 52[5]\end{array}$ & $\begin{array}{c}25 \% \\
13 / 52[5]\end{array}$ & $\begin{array}{l}17 \% * * * \\
104 / 627\end{array}$ \\
\hline Head and neck & $\begin{array}{l}25 \% \\
8 / 32\end{array}$ & $\begin{array}{c}6 \% \\
2 / 32\end{array}$ & - & - & $\begin{array}{l}33 \% \\
5 / 15\end{array}$ \\
\hline Melanoma & $\begin{array}{l}(50 \%) \\
(1 / 2)\end{array}$ & $\begin{array}{l}(0 \%) \\
(0 / 2)\end{array}$ & $\begin{array}{c}34 \% \\
16 / 47[6]\end{array}$ & $\begin{array}{c}21 \% \\
10 / 47[6]\end{array}$ & $\begin{array}{c}26 \% \\
74 / 283\end{array}$ \\
\hline
\end{tabular}

* : recalculated including only the indications of the present study.

** : include $18 \%$ of intra-modality changes and $7 \%$ combining inter- and intra- modality changes.

*** : include $5 \%$ of changes at diagnosis in 62 patients, $21 \%$ at staging in 407 patients and $10 \%$ at recurrence in 158 patients 


\section{Impact on patient staging}

The global rate of impact on patient staging was similar in our study and in the Californian study, and upstaging due to FDG PET was more frequent than downstaging.

In colorectal cancer, values of both teams were concordant.

In lung cancer, there was an agreement about a rather high frequency of downstaging $(16 \%$ or $17 \%$ ). However, this last rate given by the Californian team only applied to recurrent lung cancer. Kalff et al., 2001 reported a higher upgrading rate at $36 \%$ but the downgrading rate was somewhat lower at $12 \%$. Pieterman et al., 2000 reported higher impact both for upgrading, $41 \%$, and downgrading, $20 \%$, in preoperative $\mathrm{p}$ atients.

The results were somewhat more discrepant in lymphoma where the frequency of downstaging was similar to that of upgrading in the Californian experience but not in ours. May be the French physicians were more reluctant to consider as non malignant those nodes enlarged at CT but which do not take-up FDG.

Very few data are available concerning the impact on staging in head and neck cancers. Recently, Bender et al., 2001 mentioned upstaging $27 / 132=19 \%$ of patients due to the discovery at PET of unsuspected distant metastases.

The only values of impact rate published in melanoma are, to the best of our knowledge, $17 \%$ upstaging and $15 \%$ downstaging in California (Wong et al., 2000).

\section{Impact on patient management}

The global rate of impact on patient managem ent was greater than $45 \%$ in the Paris and the Californian (Seltzer et al., 2000) experiences. That confirms the clear clinical usefulness of FDG -PET in those cancer indications. Furthermore, the global impact rate of our team was $15 \%$ higher than the average value derived from studies of the past decade (31\% according to the Gambir's calculations (Gambhir et al., 2001)), even though it was $14 \%$ lower than that of the Californian team. In our opinion, this illustrates the importance of the "education" of the referring physician to FDG-PET. As time passed during the last decade and as the images became more extensive (whole body) and of a better quality, the clinical impact grew. By pooling the studies over a decade, Gambler calculated an impact rate on manageme nt that is probably inferior to the actual current impact in developed countries where clinical PET have been available for several years. This is illustrated by the $15 \%$ greater value obtained a soon as the first year of operating the first dedicated clinical PET machine in a French civilian hospital. The importance of a personal experience of the clinician to integrate FDG -PET in his decision making is illustrated by the gap of a similar magnitude between impacts in Paris and in California where physician were more aware of PET capacities.

In recurrent colorectal cancer, the inter-modality changes were as frequent in Paris and in California (Meta et al., 2001). However, the intra-modality changes were more frequent in California $(25 \%$ versus $7 \%$ ). Another study was recently published, reporting the Australian experience: PET directly influenced management in 59\% (60/102) of the patients (Kalff et al., 2002), a global value intermediate between our impact rate $(45 \%)$ and the Californian one (62\%), the three of them being superior to the average value of the past decade (32\% (Gambhir et al., 2001)).

In lung cancer, the impact varies according to the clinical setting. In our experience, an intermodality change occurred in $11 / 17=65 \%$ of the cases when the patient was referred for re-staging in recurrent cancer versus $21 / 55=38 \%$ in primary staging. The Californian data are in accordance with this finding, the difference being more pronounced $51 \%$ and $14 \%$ respectively (Meta et al., 2001). Kalff et al., 2001, in Australia, reported a management change in $5 / 12=42 \%$ of cases of uncharacterised solitary pulmonary nodule, 36/56 $=64 \%$ of staging cases and $21 / 29=72 \%$ of restaging cases. All their impact values were thus greater than in our experience but the trend to a greater impact in re-staging was confirmed in the three studies.

In lymphoma, the intra-modality changes were as frequent in Paris and in California (Schöder et al., 2001), but the inter-modality changes were much more frequent in California (42\% versus $16 \%$ ). This was mainly due to an earlier stopping the chemotherapeutic regimen in view of a complete response at FDG-PET in California, while chemotherapy was continued as scheduled in Paris; furthermore, surgery was more frequently used in isolated residual active tumour masses in California.

Rather few studies of impact are currently published in head and neck cancers. Gambhir 
(Gambhir et al., 2001) reported one study on only 15 patients with results similar to ours. Goerres et al. (Goerres et al., 2001) reported, in 98 patients, an impact on staging in $24 \%$ of cases and, among 39 patients treated by radiotherapy, an intermodality change in 7 cases $(18 \%)$ and an intra modality change in 6 cases (15\%), for a global impact of $33 \%$, very similar to our value.

FDG-PET can also detect occult primary cancers revealed by a metastastic lymph node of the neck. No such cases were included in the present study. The primary tumour can be localised with PET in about $40 \%$ of cases, and in several other cases, unknown secondary lesions can be brought in evidence. Both circumstances may lead to a management change, in 6/10 cases of Stokkel (Stokkel et al., 1999), 8/27 cases of Jungehulsing (Eigtved et al., 2001) and 6/34 of Eigtved (Jungehulsing et al., 2001), in total $20 / 71=28 \%$ of cases.

Melanoma was almost not present in our study, since the registered French indication, limited to primary staging, seemed of little interest to the clinicians. The Californian teams (Wong et al., 2000) reported a rate of inter-modality change of $34 \%$ and $21 \%$ for intra-modality changes. The global value derived from the calculations of Gambhir (Gambhir et al., 2001), 26\%, was lower, as in the other indications.

\section{CONCLUSION}

An impact of FDG-PET was frequently reported by the referring physician both on staging and management, as soon as during the opening year of the PET centre. The average rates were $26 \%$ for upstaging, $9 \%$ for downstaging, 37\% for inter modality management changes and $9 \%$ for intra modality management changes. The impact on patient management was therefore $15 \%$ greater than derived from the studies published during the past decade. However, in most indications, a gap in management impact was still observed between our results and the rates reported in California or Australia, which was not obvious for staging impact. We attribute this gap to a lesser familiarity of the French clinicians with PET, as they appeared to be more cautious to change therapy than to accept FDG evidences for staging the patient.

\section{RESUMO}

Avaliamos o impacto clínico do FDG-PET no estagiamento e acompanhamento de pacientes durante o primeiro ano de funcionamento do nosso centro de PET na França. Enviamos um questionário em francês, traduzido de um similar usado recentemente na Califórnia, para os médicos de cada um dos 476 pacientes que realizaram, pelo menos, um exame FDG-PET de rotina durante o ano de 2000. Das trezentos e quarenta e oito respostas (taxa de resposta $=73 \%$ ), em $26 \%$ dos casos a doença regrediu e em $9 \%$, avançou. Variações no acompanhamento intermodalidades (mudanças de uma programação terapêutica para outra modalidade) foram relatadas em 37\% dos casos e intra-modalidades em 9\%. Estas taxas de modificação foram respectivamente $38 \%$ e $7 \%$ no câncer colo-retal recorrente (153 pacientes), $47 \%$ e $7 \%$ no câncer de pulmão (118 pacientes), $16 \%$ e $23 \%$ no linfoma (43 pacientes), $25 \%$ e $6 \%$ no estagiamento de cânceres de cabeça e pescoço (32 pacientes). Quando comparados com estudos similares realizados na Califórnia, não houveram diferenças significativas entre as taxas de acompanhamento inter-modalidades. Pelo contrário, o acompanhamento das mudanças intra modalidade foram menos frequentes em nossa pesquisa, exceto para o linfoma. Globalmente, o impacto clínico da FDG-PET foi similar, com uma taxa maior de resposta na nossa pesquisa $(73 \%$ versus 35\%); esta taxa foi maior que a média de $31 \%$ encontrada para as modificações terapêuticas obtidas de um resumo tabulado recentemente para mais de 3400 pacientes.

\section{ACKNOWLEDGMENTS}

Pr Talbot insists on the fact that this su rvey was a co-operative study of the 5 nuclear medicine teams sharing the Paris PET centre i.e., apart from hôpital Tenon, those of hôpital Henri Mondor (head : Pr M. Meignan), hôpital Lariboisière (head : Pr I. Idy-Perretti), hôpital Saint-Antoine (head : Pr S. Askienazy), hôpital Saint-Louis (head : Pr J.D. Rain).He also wants to pay tribute to all the referring physicians who gave their time to fill in the questionnaires of the survey and to Miss $\mathrm{N}$ Cailleux who was responsible for their mailing, classification and processing. 


\section{REFERENCES}

Bender, H.; Straeler-Pohl, H. J.; Linke, D.; Risse, J.; Palmedo, H. and Biersack, H. J. (2001), Impact of FDG-PET on therapy management of head-and-neck tumors in patients. J. Nucl. Med., 42 : (S5), 79. [Abstract 294].

Eigtved, A.; Johansen, J.; Buchwald, C.; Theilgaard, S. A. and Hansen, H. S. (2001), Implication of FDG PET on treatment management of patients with cervical lymphnode metastaes from an unknown primary tumor. J. Nucl. Med.; 42 : (S5), 80. [Abstract 297].

Gambhir, S.; Czernin, J.; Schwimmer, J.; Silverman, D. H. S.; Coleman, R. E. and Phelps, M.E. (2001), A tabulated summary of the FDG PET literature. $J$. Nucl. Med., 42 : (S5), 1S-93S.

Goerres, G. W.; Mosna-Firlejczyk, K.; Von Schultess, G. K. and Steinert, H. (2001), Impact of positron emission tomography (PET) with 18F-fluoro-deoxyglucose on management of patients with head and neck tumors. J. Nucl. Med., 42 : (S5), 290. [Abstract 1208].

Jungehulsing, M.; Scheidauer, K.; Damm, M.; Pietryk, U.; Eckel, H. and Schicha et al. (2000), 2[F]-fluoro-2deoxy-D-glucose positron emission tomography is a sensitive tool for the detection of occult primary cancer (carcinoma of unknown primary syndrome) with head and neck lymph node manifestation. Otolaryngol. Head. Neck. Surg., 123 : (3), 294-301.

Kalf, V.; Hicks, R. J.; Mac Manus, M. P.; Binns, D. S. M. C.; Kenzie, A. F. and Ware, R. E. et al. (2001), Clinical impact of $18 \mathrm{~F}$ fluorodeoxyglucose positron emission tomography in patients with non-small-cell lung cancer : a prospective study. J. Clin. Oncol., 19, 111-118.

Kalff, V.; Hicks, R. J.; Ware, R. E.; Hogg, A.; Binns, D. and Mac Kenzie, A. F. (2002), The clinical impact of 18F-FDG PET in patients with suspected or confirmed recurrence of colorectal cancer: a prospective study. J. Nucl. Med., 43, 492-499.
Meta, J.; Safei, A.; Lu, C. S.; Seltzer, M.; Silverman, D. and Gambhir, S. et al. (2001), Substantial impact of FDG PET on re-staging of lung cancer: the referring physician perspective. $J$ Nucl Med., 42 : (S5), 150. [Abstract 562].

Meta, J.; Seltzer, M.; Schiepers, C.; Silverman, D. H.; Ariannejad, M. and Gambhir, S. et al. (2001), Impact of 18F-FDG PET on managing patients with colorectal cancer: the referring physician's perspective. J. Nucl. Med., 42 : (4), 586-590.

Pieterman, R. M.; Van Putten, J. W. G. and Meuzelaar J. J. et al. (2000), Preoperative staging of non-small cell lung cancer with positron-emission tomography. N. Engl. J. Med., 343, 254-261.

Schöder, H.; Meta, J.; Yap, C.; Ariannejad, M.; Rao, J. and Phelps ME et al. (2001), Effect of whole-body 18F-FDG PET imaging on clinical staging and management of patients with malignant lymphoma. $J$. Nucl. Med., 42, 1139-1143.

Seltzer, M. A.; Valk, P. E.; Wong, S.; Ariannejad, M.; Gambhir, S.; Phelps, M. E. and Czernin, J. (2000), Prospective survey of referring physicians to determine the impact of whole body FDG-PET on management of cancer patients. J. Nucl. Med., 41 : (S5), 108. [Abstract 428].

Stokkel, M. P.; Terhaard, C. H.; Hordijk, G. J. and van Rijk, P. P. (1999), The detection of unknown primary tumors in patients with cervical metastases by dualhead positron emission tomography. Oral Oncology, 35 : (4), 390-394.

Wong, C.S.; Valk, P.; Ariannejad, M.; Seltzer, A.; Phelps, E.; Gambhir, S. S. and Czernin J. (2000), Impact of FDG-PET on management of patients with melanoma. J. Nucl. Med., 41 : (S5), 282. [Abstract 1232].
Received: June 19, 2002;

Revised: June 22, 2002;

Accepted: June 25, 2002. 